\title{
Design and Implementation of Library Management System
}

\author{
Weihong Yang \\ People's Hospital of Zhengzhou, Zhengzhou 450000, Henan Province, P. R. China \\ tuke126@126.com \\ Corresponding Author: Weihong Yang
}

\begin{abstract}
Library is an important service department, the hospital is the core place for doctors to acquire knowledge, and for the rest and leisure of patients. Due to the unceasingly expand of hospital size and book quantity, hospital library is mainly engaged in the storage and circulation of large numbers of books. Computer technology application is the current trend for library management system, which had been widely applied. Hospital library management system is mainly developed a library management system containing books management, user management, and administrator management, renew online, message and other functions. System implemented renew and message function is one of the main characteristics of the system. Borrow in advance function refers to the readers could book in advance for the books which had been borrowed by others. The information had been recorded. When the book was returned back to library, the system could been immediately booked, and send text message or e-mail notifications to the borrower. Message function refers to that the readers could leave a message on the message board, and the administrator could manage the message function. This function enabled the interactions between readers and administrators, and help administrators improve the work efficiency. In order to meet the requirements of modern library management, and put forwarder the books management system management system design and realization scheme based on VB. This system realized the books management business's core parts, which were borrow-lend management, reader management, books management and system maintenance function.
\end{abstract}

Keywords: Library management system. VB; C/S.

\section{Introduction}

Books management system was the typical application of information management system. Its development mainly included the establishment and maintenance of database and head application development. For the former requirement to establish data consistency and integrity. The integrity required the application function, easy to operate. Based on the above consideration, this system mainly adopt VB6.0 as the front-end application development tools. SQL Server was applied to back-end database. Windows was the system platform development books management system management system. In addition, our library management system used the software engineering ideas and methods. Overall listing the structured method for system analysis and design of life, while the prototype system between step and the method of facing object [1].

\section{Demand analysis}

Demand analysis was the basis of system design. At this stage, it need to accurately obtain the user requirements, analysis of demand, thus to define system requirements. System requirements included functional requirements and non-functional requirements.

\subsection{The functional requirements}

Lend management is book-borrowing and book return business. Book borrow need to verify the legitimacy of the reader and library. Book return management to verify the legality of the book. Such as extended, requires are fine. Reader management was to maintain the reader information, including information addition, information modifying, information delete and reader information query. Books management was to operate the books information, including the new inbound, outbound, transfer and query. System maintenance was to system data maintenance, and to ensure the safety of 
system data, including information addition, users information delete, backup data and data reduction [2].

\subsection{Functional requirements}

The user system interface should be concise and beautiful. Response time referred to the corresponding time of daily transaction processing, which should be less than 3 seconds. New book storage, borrow, return the book business processing to the corresponding time should be less than 6 seconds. Business requirement was new data entry format using MARC format, book classification with reference to the Chinese Law.

\section{System design}

\subsection{Structure design}

The current popular software architecture with C/S (Client/Server) and B/S (Browser/Server) model. Although B/S structure had the characteristics of distributed, easy maintenance and less client, the system response speed was still less than C/S structure, cannot satisfy the non-functional requirements of the system. Therefore, system adopted C/S architecture model. The system architecture was shown in figure 1.

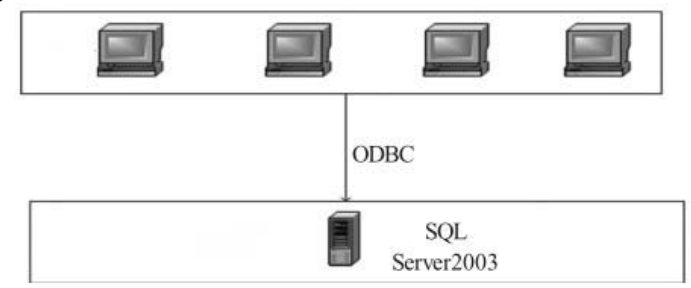

Figure 1. C/S structure

\subsection{Function structure}

Program description was used to return books. After the log in the ID, the user could operate to return the books. If confirm to the requirements of return books, the books could be return later. Functions was to achieve the function of books. The next step if any; if there was no return step, it need to research the book ID. If the number does not exist, indicated that the book doesn't exist; If the book exists for the next operation. The reduced quantity of books borrowed quantity, the library database should be increased. At the same time, it need to remind the borrower to return the book back.

\section{The hospital library management system design goal}

Design of the system implementation requirements described in the analysis phase of all display needs; design of the system could read, understand, easy to test, easy to maintain; Design of the system structure should be layered structure, thus the established between software components of control; design of the system had the characteristics of independent function modules[3]. Design of the system had the characteristics of independent function modules. The design should be able to reduce the complex connection between module and the external environment of interface. Design should be based on the software requirements analysis for information repeatable methods.

\subsection{The performance requirements of hospital management system}

Hospital required library management system was not only to meet the demand of the existing management, in order to meet future development needs, but also can meet the requirements of future development. In this paper, hospital books management system should contain following performance requirements. Firstly, the books management system of hospital user interface requirements beautiful interface simple, easy to operate, suitable for hospital doctors, patients of other users to browse and usage. The system should be practicability, convenience for user management, books management, convenient message management, books information effectively and timely update. System stability required the stable operation of the system a long period of time. 
Data centers needs to ensure data consistency within the scope of the whole hospital. The phenomenon such as reducing network errors, to prevent the system crash. System security need to establish a login user roles, password, two-way identification authentication; all types of users could be their own password modification.

\subsection{Function requirements analysis of hospital library management system}

This system adopted modular processing ideas, and realized the main functions of the modules of login, book management, user management, administrator management, book borrow, book return, renew, advance online and online message, etc. Through the cases of various types of existed books management system, the readers could view the library book for detailed information [4]. If the reader already regurgitate as a user, books management system management system's official was registered users could see the personal information could also be to change your personal information. Readers could query on their borrowing books, to evaluate borrowed books. In addition, as managers of books management system management system, besides with ordinary readers to browse website, and could also perform management. According to the state of library system, the update operation of the book information and readers' borrowing and management of readers and library. The functional requirements summarized below. Firstly, the books management should include warehousing, lend, returned, book information and other functions. Secondly, the user management should obtain user registration, login, user information modification, user permissions and other functions. Thirdly, it was the end of library information processing. Forth, return the books contained the book information processing. Fifthly, online renewal, the user had to borrow books online renew management, online query book information and advance online had borrowed books online in advance. Finally, it was the interaction of message boards, the librarian and the user platform.

\subsection{Case modeling system usage}

From the perspective of practical application, the library should be borrowed as the center to provide more diversified services. Books management system management system was a unified library and readers of books information management system. Case usage modeling was another form of demand analysis, the key was to find the participants and users cases [5]. Usage case described each of the participants how to use the system. Use case diagram showed between use cases and cases with the participants was how to connect each other. Usage case diagram for the conduct of the system, subsystem or visualization, enabling users to understand how to use these elements, and enabled developers to implement these elements. UML usage case diagram exactly described the functional requirements of the users, made the system responsibility clear, and laid the foundation of UML for system modeling. In this way, the other model diagram structure and the development relied on the use case diagram described the content, until the system could realize the functions described in the use case diagram. In the book information management system, the system of the participants were readers and administrator.

Case usage analysis should avoid the system implementation details should be considered. The actually build system and the details written in the time stream file. Its purpose is to use cases and the logical process of establishing document which details the work of the users of the system and the system itself. Event flow description was a system of "what to do", instead of "how to do". Event circulation included brief description, flow condition in advance, the main flow of events and other events and conditions. The books management system and system management had the largest operating authority, requirements were to be able to borrow library card information. To maintain the books information included the book information addition, query, modify and cancel action. Information query borrowing and lending books maturity of the information. Handing the borrowing and returning books and perform fines operations, information addition, modifying and delete information classification of books. Timely release some important information, such as student borrowing books due to the message, the museum of new books timely, so that students could get books borrowing situation and the latest collection of the library. 


\section{Conclusion}

The system was realized by structured analysis and development methods. System run well at present, although the system function was simpler, its implementation was a relief to librarians working pressure had reached the expected goal.

\section{References}

[1] H.C. Tao. Software engineering, Beijing: economic science press, pp. 292-311, 2004.

[2] L.N. Lu. Software engineer. Beijing: Economic Science Press, pp, 27-96, 1999.

[3] Z.H. Hao, F. Liu, Visual Basic 6.0 Programming Article. Beijing: Publishing House of Electronics Industry, pp.145-201, 2004.

[4] S.F. Liu, Database fundamentals and applications. Beijing: The Central Radio and Television University Press, pp.27-43, 2003.

[5] B. Wu, D.L. Lu. Visual Basic and SQL Server database application system development. Beijing: China Machine Press, pp.39-51, 2014. 